\title{
Pregnancy at the Cesarean Section Scar: Successful Management and Review of Current Literature
}

\author{
Pratibha Singh ${ }^{1}$ Sunil Raikar ${ }^{1}$ Garima Yadav ${ }^{1}$ \\ ${ }^{1}$ Department of Obstetrics and Gynecology, All India Institute of \\ Medical Sciences, Jodhpur, Rajasthan, India
}

\author{
Meenakshi Gothwal' Navdeep Ghuman ${ }^{1}$
}

\begin{abstract}
Address for correspondence Pratibha Singh, MD, Department of Obstetrics and Gynecology, All India Institute of Medical Sciences, Jodhpur 342005, Rajasthan, India (e-mail: drpratibha69@hotmail.com).
\end{abstract}

\begin{abstract}
Keywords

- cesarean scar pregnancy

- scar site pregnancy

- ectopic pregnancy

When implantation of the early embryo occurs at the scar of previous cesarean, it is called cesarean scar pregnancy. Though in uterus, it behaves like an ectopic pregnancy with risk of rupture and hemoperitoneum. A 37-year-old woman came with missed period and vague abdominal discomfort; she had a positive pregnancy test. She had previous two cesarean sections. The last cesarean section was 12 years ago and the patient was not using any contraception. Her ultrasonography (USG) was inconclusive; $\beta$ human chorionic gonadotropin was $2,980 \mathrm{mIU} / \mathrm{mL}$. Her repeat USG showed a hypoechoic area at the cesarean scar site, behind the reflection of bladder, separated from bladder by a thin layer of myometrium. She was counseled regarding the management options and prognosis. She was managed with two doses of injection. Methotrexate on day 1 and day 4 . $\beta$ human chorionic gonadotropin was repeated until it was close to normal. USG was also repeated. Cesarean scar pregnancy can be managed by many ways; the one most suitable to the patient with least side effects should be adopted, after adequate counseling of the patient.
\end{abstract}

\section{Introduction}

Location of pregnancy outside the uterine cavity is considered as ectopic pregnancy and the fallopian tubes are considered as the commonest site for it. Cesarean scar pregnancy occurs if the gestational sac is implanted in uterus at the site of previous scar of cesarean section or hysterotomy. ${ }^{1}$ This generally leads to invasion of this area by trophoblasts leading to further thinning and rupture of this area with consequent hemoperitoneum. ${ }^{2}$ Rarely cases of live births have also been reported. ${ }^{1}$ Previous uterine cesarean or hysterotomy scar is the only risk factor for this type of pregnancy. The occurrence of cesarean scar pregnancy is likely to increase due to better sonographic equipment and rising numbers of cesarean scars; presently, it is estimated to be $1: 1,800$ to 2,500 of all cesarean deliveries performed. ${ }^{3}$

Though the resolution of sonography machine has improved considerably, diagnosis of cesarean scar pregnancy is challenging, often being confused as failing intrauterine pregnancy and inevitable abortion. It has been reported that as many as $76 \%$ of cesarean scar pregnancy might be

DOI https://doi.org/ 10.1055/s-0040-1709225 ISSN 0379-038X. misdiagnosed ${ }^{4,5}$ and can be challenging to the obstetricians. This can lead to avoidable complications, for example, hemoperitoneum, shock, emergency hysterectomy, and rupture of uterus in future pregnancy. ${ }^{5}$

We report this case not only for its rarity, but also for timely diagnosis, and successful treatment after discussing all options of management with the patient.

\section{Case Report}

A 37-year-old para 2 woman came with vague lower abdominal discomfort and missed period. She had previous two cesarean sections; the last was 12 years back. She was not using any contraception. She was a known diabetic for the past 5 years and was on oral hypoglycemic agents. She did a urine pregnancy test at home, which was positive. As she did not want this pregnancy, she went for medical termination of pregnancy to a local practitioner and an abdominal ultrasonography (USG) was done which failed to show any gestational sac. So her $\beta$ human chorionic gonadotropin (HCG) was done, it was $2,980 \mathrm{mIU} / \mathrm{mL}$.

(C) 2020. National Academy of Medical Sciences (India).

This is an open access article published by Thieme under the terms of the Creative Commons Attribution-NonDerivative-NonCommercial-License, permitting copying and reproduction so long as the original work is given appropriate credit. Contents may not be used for commercial purposes, or adapted, remixed, transformed or built upon. (https://creativecommons.org/licenses/by-nc-nd/4.0/).

Thieme Medical and Scientific Publishers Pvt. Ltd. A-12, 2nd Floor, Sector 2, Noida-201301 UP, India 
She came to our hospital with this history and reports of USG and $\beta$ HCG. Her examination revealed stable vitals, soft abdomen. Pelvic examination showed healthy cervix and soft anteverted uterus without any cervical motion tenderness. Her transvaginal USG revealed endometrial thickness of $10 \mathrm{~mm}$, a hypoechoic area located anteriorly above the internal os, close to the bladder reflection ( - Fig. 1). It had a fetal pole corresponding to 7 weeks of pregnancy. The myometrium over the sac was thinned out. Diagnosis of cesarean scar pregnancy was made on suggestive USG picture. Patient and her husband were informed about the case and the problems associated with it. Management options were discussed with them, as it was an unwanted pregnancy she opted for medical management with methotrexate.

Patient was given methotrexate injection $(1 \mathrm{mg} / \mathrm{kg}$ body weight) on day 1 . Her $\beta$ HCG was repeated after 48 hours which was $3,250 \mathrm{mIU} / \mathrm{mL}$ and her complete blood count was also repeated which was within normal limits. She was given a second dose of methotrexate injection on day 4. Her repeat $\beta$ HCG showed a declining trend and was $2,220 \mathrm{mIU} / \mathrm{mL}$. She was followed with weekly $\beta$ HCG, which was $5 \mathrm{mIU} / \mathrm{mL}$ after 5 weeks (-Table 1 and - Fig. 2). She did not develop any problems with methotrexate injection like jaundice, mouth ulceration, gastritis, urinary problems, etc.

Transvaginal sonography was repeated after 2 weeks and 4 weeks; which at 2 weeks showed a gestational sac was much smaller in size and crumpled, and at 4 weeks it was undetectable.

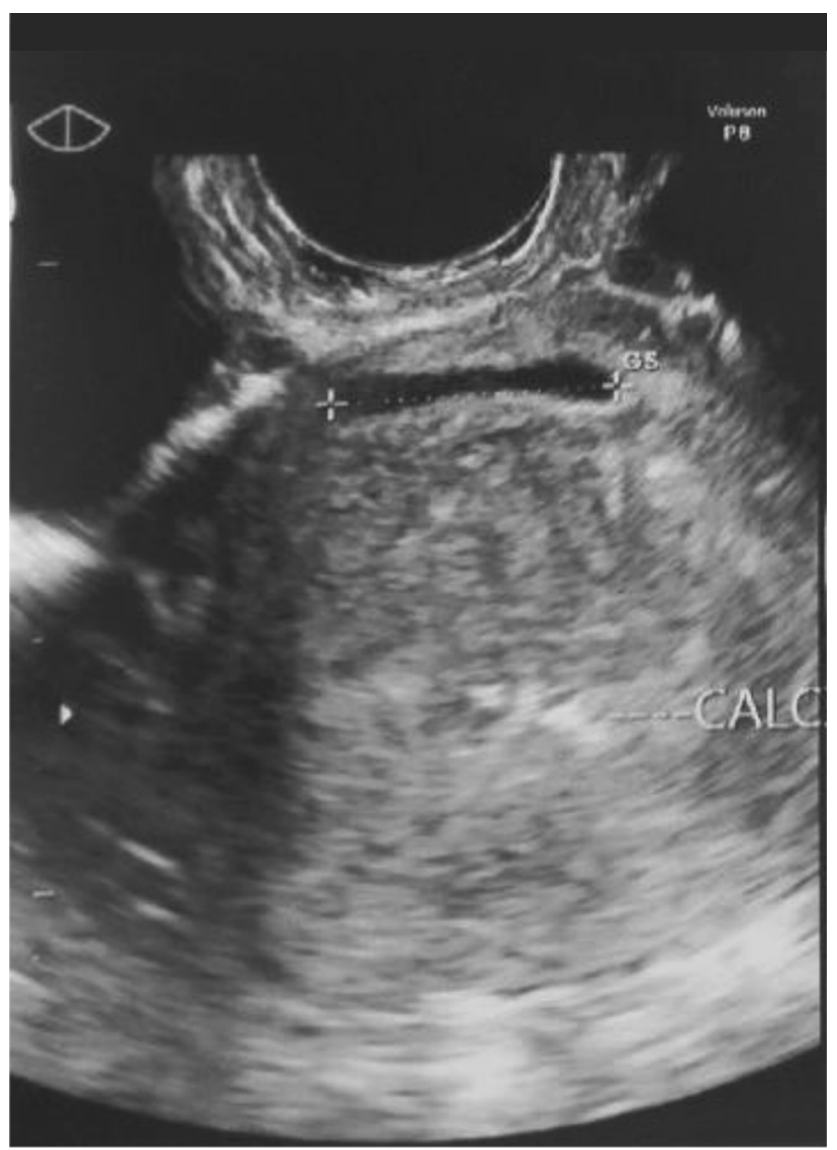

Fig. 1 Cesarean scar pregnancy.
Table 1 Timeline of management with $\beta$ human chorionic gonadotropin and USG

\begin{tabular}{|c|c|c|c|}
\hline No. & Day & $\beta$ HCG (mIU/mL) & Management done \\
\hline 1 & 0 & 2,980 & \\
\hline 2 & 1 & & $\begin{array}{l}\text { Methotrexate injection } \\
\text { (1 } \mathrm{mg} / \mathrm{kg} \text { body weight) }\end{array}$ \\
\hline 3 & 3 & 3,250 & $\begin{array}{l}\beta \text { HCG showed a rise } \\
\text { after } 48 \text { hours. }\end{array}$ \\
\hline 4 & 4 & & $\begin{array}{l}\text { Second dose of metho- } \\
\text { trexate injection given }\end{array}$ \\
\hline 5 & 5 & 2,220 & Falling trend of $\beta$ HCG \\
\hline 6 & 7 day & 960 & Follow-up \\
\hline 7 & 2 weeks & 440 & $\begin{array}{l}\text { TVS-tiny hypoechoic } \\
\text { crumpled sac seen }\end{array}$ \\
\hline 8 & 3 weeks & - & Follow-up \\
\hline 9 & 4 weeks & 67 & $\begin{array}{l}\text { TVS repeated-no sac } \\
\text { seen }\end{array}$ \\
\hline 10 & 5 weeks & 5 & Follow-up \\
\hline
\end{tabular}

Abbreviations: HCG, human chorionic gonadotropin; TVS, transvaginal sonography.

- Fig. 1 shows transverse section showing gestational sac in the myometrium close to bladder reflection anteriorly and some calcification at the endometrial cavity.

\section{Observation}

The management and the follow-up of this patient are depicted in - Table 1. Trends in beta HCG are depicted in -Fig. 2.

\section{Discussion}

Cesarean scar pregnancy is a unique type of pregnancy, though present in uterus many like to consider it as ectopic pregnancy. A history of previous delivery by cesarean section is needed for the diagnosis of cesarean scar pregnancy. A history of previous uterine cesarean scar, missed period/ positive urine pregnancy test, and the typical USG picture is required for the diagnosis of cesarean section scar pregnancy. Transvaginal sonography gives a better resolution; and empty uterine cavity and empty endocervical canal, gestational sac at the lower uterine part near the bladder reflection, away from the uterine cavity with rim of myometrium over it gives a clue for diagnosis. Fetal pole and yolk sac may or may not be present depending on the duration of pregnancy. Close reflection of bladder peritoneum near the lower part of cervix tells about the location of previous scar of cesarean. A closed cervix and empty cervical canal helps in ruling out incomplete abortion and cervical ectopic pregnancy, an important differential diagnosis. ${ }^{5}$ 3D and 4D USG images give accurate location of this type of pregnancy, where images can be reconstructed to see gestational sac away from the endometrium, at the bladder reflection and thin stretched myometrium over it. Adding color to it shows high vascularity, and better delineation of blood vessels can be seen. 


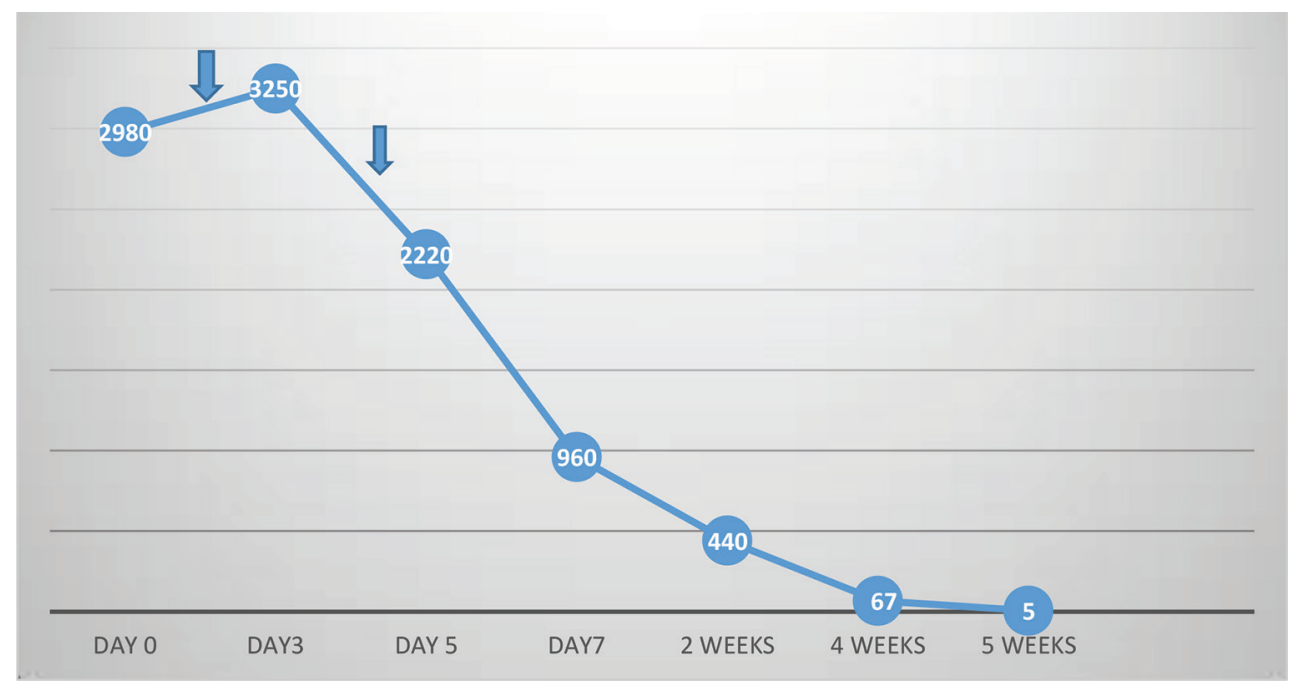

Fig. 2 Trends of $\beta$ human chorionic gonadotropin with methotrexate injection (arrow points to administration of methotrexate injection).

Treatment of cesarean scar pregnancy needs to be individualized. If the gestational sac is empty, or the fetal pole or cardiac activity is not seen and the $\beta$ HCG is stationary or suboptimally rising a possibility of failing pregnancy deserves careful follow-up by transvaginal sonography and estimation of $\beta$ HCG. However, some may still prefer to give methotrexate injection in such condition. A rising HCG and/ or appearance of cardiac activity in such a situation should be treated with methotrexate, which can be given as single dose or multiple doses. Both of them have been equally effective in treating ectopic pregnancy; however, multiple doses of methotrexate are associated with more side effects. ${ }^{6}$ Intralesional methotrexate may be more effective if the size of sac is more than $5 \mathrm{~cm}$ and presence of cardiac activity and if future fertility is desired. ${ }^{7}$ Alternatively uterine artery embolization and local Methotrexate 7,8 may also be effective. There have been reports of treating cesarean scar pregnancy vaginally by suction evacuation under USG guidance, but brisk bleeding is a risk which may require local balloon tamponed. ${ }^{8}$ If the patient wishes to continue pregnancy risk of hemorrhage, adherent placenta, uterine rupture necessitating hysterectomy and need for a repeat cesarean needs to be counseled to her by the treating physician. ${ }^{5}$ If the patient presents late after rupture, excision of the pregnancy or even hysterectomy may be needed. Intralesional methotrexate guided by USG has also been done ${ }^{9}$ with success. Methotrexate systemic as single or multiple doses or intralesional is the commonly preferred treatment. ${ }^{8}$ Intralesional methotrexate is a good choice if the pregnancy has cardiac activity and is 6 to 8 weeks in size. Side effects of methotrexate are more with multiple dosing. If the pregnancy grows toward the uterine cavity after implantation, it is possible to have term pregnancy. Evidence-based management of cesarean scar remains unclear; hence, these patients need to be individualized for management. ${ }^{10,11}$

In our patient, we had given two doses of methotrexate injection as the $\beta$ HCG was raised after the first injection. She did not develop any systemic side effects of methotrexate.
Individualized treatment according to patient's characteristics and wishes taking care of contraindications and side effects should be practiced to have the best results. Early pelvic USG, preferably transvaginal is recommended for early and diagnosis of this condition. It also stresses the need for effective contraceptive practices to avoid unwanted pregnancies.

\section{Conclusion}

Cesarean scar pregnancy is likely to rise in incidence due to increasing numbers of cesarean sections. Timely diagnosis with typical USG characters need to be looked for early diagnosis. There is no single best treatment for this condition. Individualized management of patients taking care of her wishes, contraindications, and side effects can give satisfactory results.

\section{Conflict of Interest}

None declared.

\section{References}

1 Timor-Tritsch IE, Monteagudo A, Santos R, Tsymbal T, Pineda $\mathrm{G}$, Arslan AA. The diagnosis, treatment, and follow-up of cesarean scar pregnancy. Am J Obstet Gynecol 2012;207(1): 44.e1-44.e13

2 Gao L, Huang Z, Zhang X, Zhou N, Huang X, Wang X. Reproductive outcomes following cesarean scar pregnancy - a case series and review of the literature. Eur J Obstet Gynecol Reprod Biol 2016;200:102-107

3 Fu LP. Therapeutic approach for the cesarean scar pregnancy. Medicine (Baltimore) 2018;97(18):e0476

4 Wang YL, Weng SS, Huang WC, Su TH. Laparoscopic management of ectopic pregnancies in unusual locations. Taiwan Obstet Gynecol 2014;53(4):466-470

5 Timor-Tritsch IE, Monteagudo A. Unforeseen consequences of the increasing rate of cesarean deliveries: early placenta accreta and cesarean scar pregnancy. A review. Am J Obstet Gynecol 2012;207(1):14-29 
6 ACOG Practice Bulletin No. 191, Mar 2018. Available at: https:// www.acog.org/Clinical-Guidance-and-Publications/PracticeBulletins/Committee-on-Practice-Bulletins-Gynecology/ Tubal-Ectopic-Pregnancy. Accessed March 6, 2020

7 Seow KM, Wang PH, Huang LW, Hwang JL. Transvaginal sonoguided aspiration of gestational sac concurrent with a local methotrexate injection for the treatment of unruptured cesarean scar pregnancy. Arch Gynecol Obstet 2013;288(2):361-366

8 Wang DB, Chen YH, Zhang ZF, et al. Evaluation of the transvaginal resection of low-segment cesarean scar ectopic pregnancies. Fertil Steril 2014;101(2):602-606
9 Yin XH, Yang SZ, Wang ZQ Jia HY, Shi M. Injection of MTX for the treatment of cesarean scar pregnancy: comparison between different methods. Int J Clin Exp Med 2014;7(7):1867-1872

10 Gonzalez N, Tulandi T. Cesarean scar pregnancy: a systematic review. J Minim Invasive Gynecol 2017;24(5):731-738

11 Jurkovic D, Hillaby K, Woelfer B, Lawrence A, Salim R, Elson CJ. First-trimester diagnosis and management of pregnancies implanted into the lower uterine segment cesarean section scar. Ultrasound Obstet Gynecol 2003;21(3):220-227 